\title{
Process and Knowledge Management in a Collaborative Maintenance Planning System for High Value Machine Tools
}

\author{
Shan Wan ${ }^{\mathrm{a}}$, DongboLi ${ }^{\mathrm{a}, *}$, James Gao ${ }^{\mathrm{b}}$, Rajkumar Roy ${ }^{\mathrm{c}}$ and Yifei Tong ${ }^{\mathrm{a}}$
}

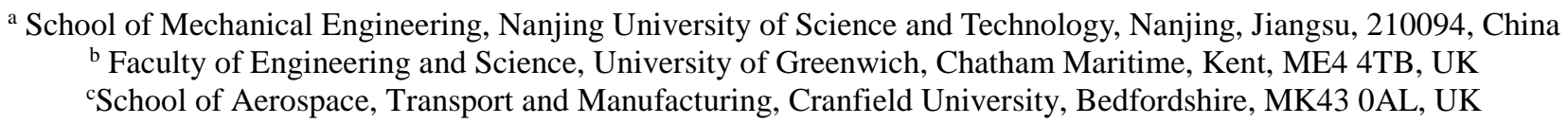

* Corresponding author: Email address: db_ws@ hotmail.com, Phone: +86(025)84315446, Fax: +86(025)84315831

\begin{abstract}
Product manufacturers are extending their responsibilities in the whole life cycle by providing services to their customers. In recent years, product service system has become an important research topic to address the special requirements in the new service driven business model. High value machine tools in modern manufacturing factories are special products: they are regarded as 'products' from maintenance point of view, and they also manufacture other products. In the new business model, the quality and behavior of a machine tool not only affect the quality of the parts it manufactures, but also affect the profits of the machine tool's manufacturer. However, in the research area of product service systems and related computerized maintenance systems, there is a lack of investigation into the special nature, problems and requirements of high value machine tool maintenance, which are very important in modern digitized manufacturing systems. Therefore, this research investigated the various relationships between different stakeholders in the machine tools' lifecycle, focusing on knowledge management, communication and the decision-making processes. This research also explored the potential application of advanced content management systems, which are widely implemented in the financial, business and government organizations, in the manufacturing engineering domain which has been dominated by traditional engineering information systems. A prototype collaborative maintenance planning system is proposed, developed and evaluated using an example machine tool, which indicated that significant improvement could be achieved and the content management technology has a number of advantages over the traditional engineering information systems, such as computer aided engineering, product data and lifecycle management, and enterprise resource planning systems, in managing machine tool maintenance and service information including dynamic and unstructured knowledge.
\end{abstract}

Keywords: Product Service System, Content Management System, Knowledge Management, Process Management, Machine Tool Maintenance and Service

\section{Introduction}

One of the main trends in the manufacturing industry is that product manufacturers are expanding their role in the value chain by offering advanced services or complete solutions which are closely coupled to their products, also called servitisation [1,2].To address the challenges and requirements of the new service driven business model, as opposed to the traditional product and technology focused approach, product-service systems have been proposed as potential solutions, enabling tools and an important research topic[3]. This paper presents research and development of a collaborative maintenance planning system for high value machine tools in modern manufacturing factories. Machine tools are regarded as 'products' in product-service systems, which also manufacture other products from manufacturer's point of view. In sophisticated and high value manufacturing systems, maintenance plays important role in keeping or renovating the manufacturing equipment in or to its designed functionality. Machine tool maintenance and services include scheduled maintenance, unscheduled maintenance, repairs, calibration and testing, involving internal and external stakeholders [4].

In digitised and globally distributed manufacturing systems, the maintenance and service providers are facing the challenges in managing increasing amount of information and data related to products and maintenance operations including associated knowledge, lessons learnt and best practices. For example, voice from customers about equipment reliability are gathered, but not fed back to the Original Equipment Manufacturers (OEMs) for the improvement of new product design. Some information in current practice is sometimes not up-to-date, such as scheduled maintenance procedures when equipment is changed. Poor communication and sharing of information between various stakeholders because of distrust affects effective collaboration in the planning and scheduling of maintenance tasks and supporting resources. Current information and knowledge management systems are mainly designed and implemented for mainstream product design and manufacturing operations, even product lifecycle management (PLM) systems rarely support product maintenance and service tasks [5]. 
Industrial product-service systems are recently being developed by researchers mainly for large and complex products or facilities [6,7]. However, in the literature there is little reported research work that has been devoted to the maintenance and service of machine tools in the product-service systems research area [8]. Therefore, the research reported in this paper aimed at exploring the special requirements of complex machine tool maintenance and services, various relationships with stakeholders and the processes of operations. The focus will be on knowledge management, communication and decision support processes.

Another main aim of this research is to explore the capability, feasibility, advantages and disadvantages of Content Management Systems (CMS) in managing engineering information and knowledge. Traditional engineering information systems such as database, enterprise resource planning (ERP) and PLM systems have rigid structures. They are good at dealing with numerical data but difficulty to respond to changes. As pointed out by Metso et al[4], not only the sophisticated Information and Communication Technology (ICT) systems, but also human and organisation that are key elements in successful maintenance. The required ICT system should provide a platform for stakeholders to exchange information and knowledge timely, and allows them to look for the right information more quickly and reuse lessons learnt.

CMS are being taken as one of the most important ICT tools in managing organization information and knowledge, especially unstructured information and knowledge, in business, media, financial and social applications [9],but very few applications in the areas that are dominated by traditional engineering information systems. Due to its high flexibility and extendibility, and the advantages in managing unstructured information, compared with traditional engineering systems, this research project used an Open Source CMS as the platform for the development of a collaborative maintenance and service planning system for high value machine tools focusing on process and knowledge management involving stakeholders within and beyond a manufacturing organisation.

\section{Previous Research in Computerised Maintenance Management}

Relevant previous research and development is broadly in the area of E-maintenance, which has been proposed since early 2000, as a key element of e-enterprise, and also an aspect of growing importance in e-manufacturing [10]. In a manufacturing system, e-maintenance is a concept by which the operations of manufacturing equipment are enabled to achieve predictive near-zero-downtime performance through a maintenance management system that monitors plant floor assets by integrating supervisory control, data acquisition and business systems, using Web-enabled and tether-free (wireless) technologies[11]. E-maintenance has the potential to improve the collaboration and cooperation between different maintenance actors (experts, maintainers), enterprise departments (maintenance, production, procurement) and external business partners (spare parts suppliers, machine manufacturers, machine users).One important industrial requirement is to achieve knowledge-based operation and maintenance, and e-maintenance systems should allow different people to learn from past experiences[10].Using advanced ICT tools, e-maintenance solutions allow users to make decisions more effectively and efficiently with "just-in-time access" to maintenance related information[12].

Typically, e-maintenance solutions are implemented as a Computerized Maintenance Management System (CMMS), through which the users can access maintenance data and information [13]. A CMMS system includes a number of functions such as equipment management, work orders, preventive maintenance instructions, and spare parts control. Traditional CMMS is normally a standalone system that can be used for complex maintenance operations conducted in a plant $[14,15]$.As the manufacturing equipment is arranged with production tasks every day, maintenance planning has to be carried out jointly with production planning. The on-line monitoring of machine tool performance and in-process inspection of machined parts should be linked to machine tool maintenance as well, especially. Li et al $[16,17]$ reported an integrated on-line monitoring and inspection system based on an innovative dynamic feature concept as the basis for modelling dynamic production information to achieve accurate machining process control. In their 
dynamic feature model, the various relationships between the interim geometry of a part and associated machining characteristics have been investigated and dynamic information linked to different interim feature states have been represented. Furthermore, CMMS systems should be integrated with other manufacturing execution systems such as ERP and dynamic on-line machine tool monitoring and part inspection systems, if appropriately doing so, CMMS will be a critical and useful tool to manage maintenance activities and improve manufacturing process performance [18]. A CMMS stores a large amount of data, information, previous maintenance cases and best practices including equipment number, failure mode, diagnosis method and maintenance solutions.

However, there are some common limitations in current CMMS [19]. For example, technical documents, drawings and instructions in other systems are not easily accessible, even the information stored in the same system is difficult for users to search and get the right information quickly. The incompatibility with other information systems such as production management, spare parts inventory and purchasing systems makes it difficult for users to make decisions when relying on information stored in elsewhere, and need manual input of information leading to low accuracy and efficiency. The incompatibility in spare parts systems may lead to the confusion and delay of parts delivered since the maintenance engineer and the spare parts supplier are using different systems. There are inconsistent, incomplete and not up to date instructions for engineers to undertake maintenance tasks. Poorly designed user interface and lack of visualized presentation of maintenance information as tables or images may reduce the efficiency of understanding current situations. Furthermore, there is a lack of knowledge sharing mechanism in the system for maintenance engineers to learn from best practices and lessons learnt [8].

Therefore, this research investigates and uses the latest ICT technologies for applications in engineering and also in other sectors, to improve current computerised maintenance management systems for applications in modern digitised manufacturing systems concerning the maintenance of high value machine tool. The main objectives are to develop a collaborative maintenance planning system to be used by different stakeholders including machine tool users, manufacturers, part suppliers and service providers, consisting of the following functions (or modules):

- a product knowledge management module to manage all information and knowledge related to machine tools, their components failure modes and level of maintenance status;

- a machine tool maintenance scheduling module for resource allocation and method selection in the context of real production operations;

- a knowledge base including previous failure cases, correction methods used, resources allocated, and lessons learnt; and

- a corrective maintenance module to search and reuse the above established knowledge base to plan for correction of random failures.

An Open Source CMS Drupal was used to implement the proposed system.Content management in enterprises is called Enterprise Content Management [20].CMS have been widely implemented in the business, media and financial sectors [21]. Knowledge generation is highly associated with content management. An organization's performance in terms of productivity, quality, profitability and customer satisfaction, is significantly impacted by effective content stewardship by using appropriate information technology. In academic research, Open Source CMS have been explored to manage information and knowledge (especially unstructured) and business processes [9,22]. For example, Clair [9] implemented CMS for libraries to deal with issues of metadata management, such as the responsibility, standards, workflows and barriers of managing it. Stacciniet al. [23] reported a collaborative distance learning platform developed using an Open Source CMS. However, there were a lack of research and implementation of CMS in engineering applications to manage data, information, knowledge and process related to engineering product design, manufacturing and maintenance.

\section{The proposed collaborative maintenance planning system}

The main stakeholders for the machine tool maintenance and service are machine tool manufacturers, machine tool users (engineers and operators in manufacturing systems), maintenance and service providers and parts suppliers (see Fig. 1). Machine tool users are responsible for operating the machine tools correctly, ensuring the machine tools are in good conditions, arranging scheduled 
maintenance and services of machine tools in line with the overall production plan, as well as requesting unscheduled maintenance and service to the its manufacturer once a machine tool is broken down unexpectedly. The users will also provide feedback about the machine tool quality issues to the manufacturer. The information systems used by the users are enterprise resource planning (ERP), Manufacturing Execution System (MES) and Supply Chain Management (SCM) System.

The responsibility of the machine tool manufacturer is to provide machine tools as products with good quality as well as maintenance manuals (including scheduled maintenance and services) to machine tool users. The manufacturer will deal with maintenance and service requests from users, assign maintenance and service provider and order parts from part suppliers. Feedback from users will be recorded and analysed for future improvement. The information systems used by the manufacturer are Customer Relationship Management (CRM), SCM, ERP and MES systems.

The service provider, once receives a request from the manufacturer will make a maintenance plan according to current work orders and monitored machine performance data. The scheduling and execution of the maintenance work will be in line with the machine tool user's production planning. The service provider can be either the internal maintenance department of the user, or the manufacturer's maintenance department, or a third-party service provider. Meanwhile, the service provider will request for materials and spare parts from the machine tool manufacturers as and when needed. The manufacturers receive the part requests and ask part suppliers to provide parts to the service providers as request. The information systems used by the service provider is CMMS. The information systems used by the part supplier are ERP and MES.

The role of the proposed collaborative maintenance planning system (CoMPS) is to provide an integrated platform for different stakeholders involved in the lifecycle of machine tools, to communicate, share information and knowledge, and co-operate in the maintenance and service activities, i.e., planning and scheduling, allocating resources, analysing and diagnosing monitored machine tool performance data, ordering and delivering spare parts, and executing scheduled and un-scheduled maintenance and services. The data, information and knowledge will be recorded, captures and stored in the supportive database which can be accessed and used by all stakeholders in a controlled manner. The feedback from the users and maintenance providers to the machine tool designer (which can be internal or external to the machine tool manufacturer) is used for improvement of existing and new machines.

The design department manages product models of individual machine tools, normally stored in PLM system, consisting of bills of materials and supplier information about every single part which ensure the right version of spare parts and suppliers are ordered at request. The collaboration network is Web-based and supported by advanced computing and content management technologies, and provides all the stakeholders with full and real-time information, which can be achieved by integrating with their internal management systems as shown in Fig. 1. 


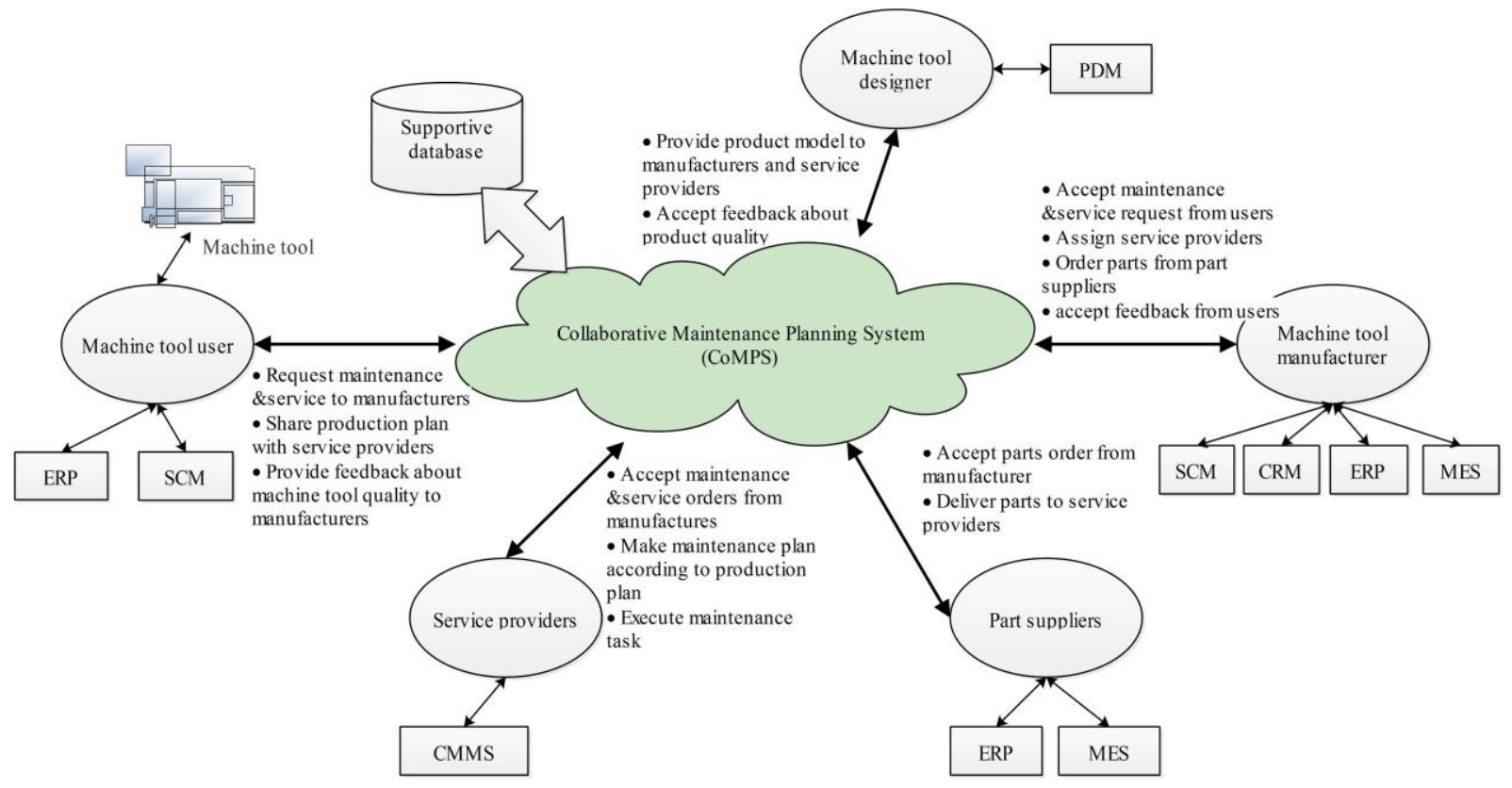

Fig. 1 The relationship between stakeholders and the role of the collaborative maintenance planning system

In summary, the proposed system would significantly enable collaboration and improve the efficiency and effectiveness of high value machine tool maintenance and services in the following aspects:

- Timely sharing of data, information and knowledge: when machine tool users request services via the internet based network, machine tool manufacturers and service providers can easily access and make use of the information and knowledge including best practice and lessons learnt stored by the users and previous service providers;

- Process integration: maintenance cannot be carried out within one company. It is a co-operating process of different partners. For example, the efficiency of part supplying process will directly affects the efficiency of maintenance execution process, and hence the final maintenance and service satisfaction. The business and operational processes of all partners would be integrated and visually presented for easy referencing;

- Organisation integration and inter-operability: stakeholders in different lifecycle stages such as machine tool users, machine tool designers and manufacturers, service providers and part suppliers from different organisations distributed in various geographical locations can be connected through the shared platform;

- System integration: CoMPS allows integration with different management systems in each stakeholder to coordinate its internal functions. For example, the customer and product information from the CRM system of the machine tool manufacturers can be fed back to the SCM system, which is used for sales decision-making. Customer feedback about machine tool quality can be taken into account for improving maintenance and service. The system can also coordinate maintenance planning from service providers with the production plans from the ERP system used in the manufacturing system, as well as the planning of part delivery and production from the ERP system within part suppliers.

\section{Implementation of the maintenance planning system using content management tools}

\subsection{System architecture of CoMPS}

The architecture of the proposed collaborative maintenance planning system (CoMPS) is shown inFig. 2. It consists of five layers, i.e., Machine tools (product) and their working environment layer, Knowledge bases layer, Development technologies layer, Modules layer and Stakeholders layer, which are described below:

- In the 'Machine tools (product) and their working environment' layer, machine tool performance is monitored by sensors installed on the machine tools. The quality of the machine tools and the manufactured parts by the machines tools are inspected during production.

- In the 'Knowledge bases' layer, monitoring signals and inspection results are stored and 
analysed. Failure cases are classified and stored with correction methods, resources available and used for specific cases, knowledge including lessons learnt for different failure modes/patterns; Maintenance solutions can be planned based on previous cases and associated knowledge.

- In the 'Development technologies' layer, are the tools used to implement the system such as: Open Source content management system Drupal, an integrated installation package under Windows environment: WAMP, i.e. the application integration of Apache Web server,
PHP interpreter and MySQL database; Hypertext Pre-processor: PHP to support Drupal development.

- In the 'Modules' layer, different functions are developed, such as product knowledge management, corrective maintenance planning, scheduled maintenance planning, as well as knowledge sharing.

- In the 'Stakeholders' layer, through the support of the internet, stakeholders can communicate and collaborate by interacting with the system modules.

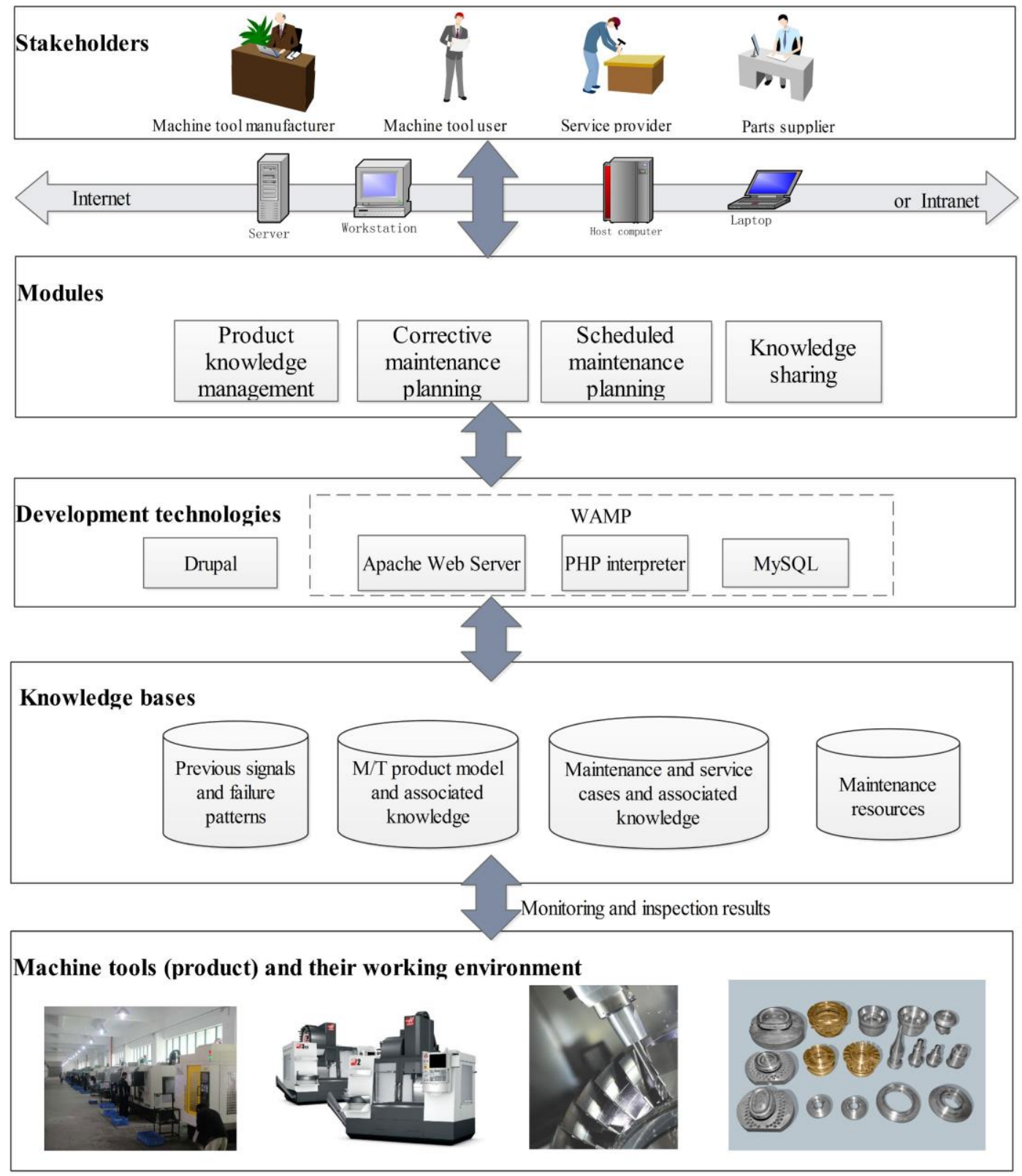

Fig. 2 The system architecture of CoMPS

\subsection{Implemented modules using Drupal}

The main development tool is an Open Source content management system Drupal. There are different definitions for content management systems. The definition given by Patel et al [21] is: a system that allows the application of management 
principles to contents. Drupal is one of the three mostly widely used content management systems within organisations (the other two are Wordpress and Joomla). Drupal is a Web content and experience management system, and also an enterprise collaboration and social software. It has advantages in managing enterprise knowledge and enhancing collaboration within organisations over the other two [24].

Drupal is a content management system and also a content management framework, one system that tries to have the strength of both, but without their deficiencies. It is an ideal content management solution for non-technical users with simplicity and flexibility. Modules provide Drupal the advantage in simplicity while nodes provide Drupal the advantage in flexibility. Users could build different types of sites by combining different modules as long as they have imagination; Drupal treats most content types as variations on the same concept: a node. A node holds the structured information pertaining to Static pages, Blog posts, and news items (such as title, author, content, date); while the Menu system, as well as Taxonomy and Views (a list of contents) creates information architectures; The theme system along with other display modules like panels controls how all this looks to site visitors.

In order to develop applications using Drupal, it has to be clear about how information flows between the system's layers. There are five main layers to be considered (as seen in Fig. 3) [25]: The data layer collects data and contents. In Drupal, a piece of content is called a node, and the content type of the node will define what fields are included with it. The Modules layer provides display function, allows data to be displayed in different ways, such as Calendar Module allows contents to be shown in a calendar. View Module allows different contents to be displayed in different view format such as Entity Reference or Table List. Blocks and Menus layer is the outputs from Modules. The outputs can be displayed as blocks or menu format, and can be put into a specific region on a page. Then the User permissions layer sets up the user permissions backend. The Template layer allows all the data, content or knowledge to be displayed as a certain site format, which is also called site theme. Three modules have been developed using Drupal, i.e., Product knowledge management, Maintenance and service planning, and Knowledge sharing.

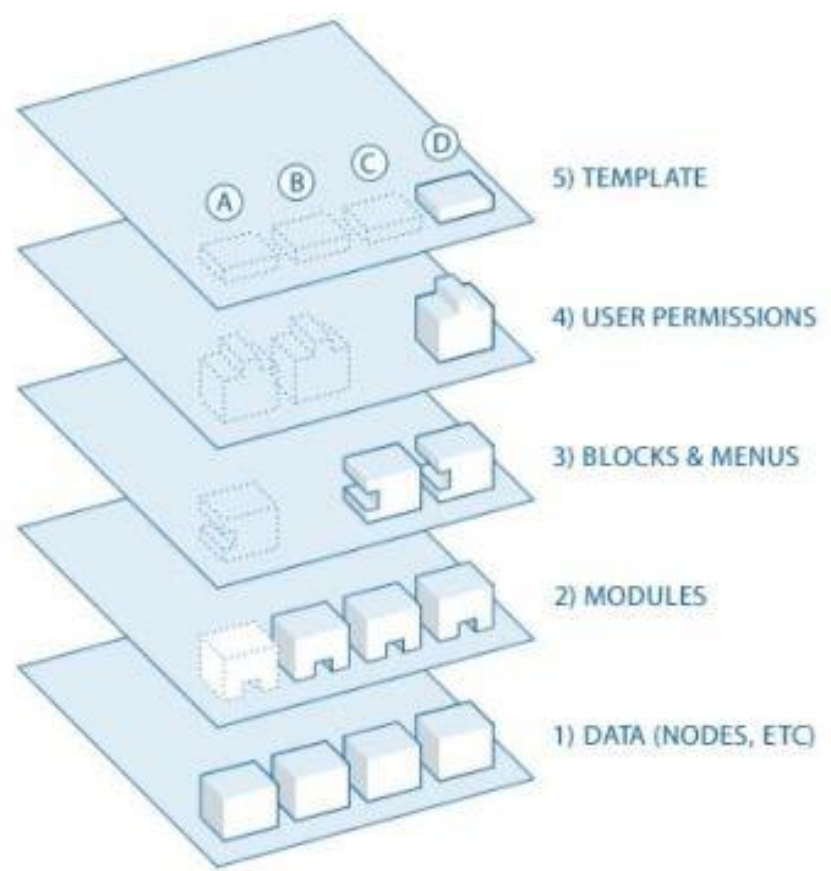

Fig. 3 Five layers of Drupal [25]

4.3 Corrective and Scheduled maintenance planning using CoMPS

Two modules have been developed using Drupal for Corrective maintenance and Scheduled maintenance planning respectively. For Corrective maintenance, i.e., when a machine tool fails unexpectedly, the service has to be requested by the machine tool user to the manufacturer, who will then assign the task to a service provider according to the requirements and constraints. Then maintenance plan and execution will be conducted by the service provider. During the planning, spare parts, consumables and tools will be ordered from parts or tools suppliers. This process involves various stakeholders to complete, thus a clear management workflow that allows them to collaborate with each other is necessary.

The workflow for Corrective maintenance planning in CoMPS is controlled by the Maestro Workflow Module backend by which the collaborative workflow is created. Each workflow has a start and end box to control the start and end time. For example, in the workflow shown in Fig. 4, it starts with creating a service request. The blue boxes are "content type task" which allow users to add values. The yellow boxes are "if-then" condition to judge which way to follow, and the grey boxes are functions that determine different results. These boxes are assigned to different users who have certain roles such as initiator, manager and engineer, and they can execute different tasks such as request services, assign engineers, response to requests and give feedback.
Each workflow backend is a template 
according to which the workflow works. Through the control of this workflow module, different stakeholders participating in this workflow could collaborate by operating a task console frontend, also provided by this Maestro module (as shown in Fig. 5). Each stakeholder roles will see their own list of tasks according to the workflow definition above. A task will appear in or disappear from the list when the task is finished by a role in the upper flow or himself respectively. Fig. 5(a) shows the machine tool user's task console. They can select the workflow template from the dropdown box. The "Service request" template is shown, then the task name "Create the service request" appears in the list. The user can click into the link and fill in related contents, after this task is finished which means the user submitted the service request, the task will go to the next role's task console, which is the manufacturer task console as shown in Fig. 5(b). The task name is changed according to what this role should do. Here it is "Review/Assign request", after someone is assigned to do this maintenance task, the assignee (whoever is assigned) will see the "View and Give solutions" task name on the task console. The rest can be done in the same manner until the task is finished.

Based on this workflow, different stakeholders could integrate their processes into the maintenance service process. For example, manufacturers can obtain feedback of machine tool's quality through requesting services and make some analysis; information from machine tool users could timely be reflected by requesting services; this process has to be finished by different stakeholders, and once one task is interrupted by a certain organization, the process would not be finished. In this way, the organization integration is achieved through this workflow.

For Scheduled (routine) services, the machine tools' particularity has to be taken into account, because the machine tool on one hand is a product of the manufacturer, on the other hand is a type of machining equipment in manufacturing systems of the machine tool users. Thus the service scheduling should consider knowledge from both stakeholders. With the Calendar Module developed using Drupal, engineers from manufacturing systems where the machine tool operates can add schedules based on machine tools' machining or production scheduling, machine tool manufacturers could add recommending service schedules during the product is designed. After created, both machining schedules and service schedules can be displayed and in different colours. For example, machining schedules are displayed in red, and service schedules are displayed in green. With different colours, confusion and conflicts can be avoided when creating another schedule. Different views of calendar events can also be generated such as month, week, day and year (see Fig. 6).

This calendar integrates the machine tool production schedules from machine tool users and service recommendations from manufacturers, with service providers to make further service plans. In addition, lessons learnt about maintenance and service practices can be generated as a book navigation link to be shown on the scheduling page (on the right sidebar of the screenshot). Service providers could learnt from previous knowledge easily, thus due to the dynamic information and intensive knowledge required by the production schedules, this system could help to achieve timely sharing data, information and knowledge between different stakeholders. Furthermore, through this system, the service provider and the machine tool user will know quickly if there is a conflict; and if there is a conflict between them, the service provider and machine tool user will consult each other and re-schedule it quickly to finish the task. From this point of view, this system could enhance the efficiency and effectiveness of machine tool maintenance and services. 


\section{Service request}

Enable Animation: $\nabla$ Snap to Grid: $\square$ Snap to Objects: $\nabla$

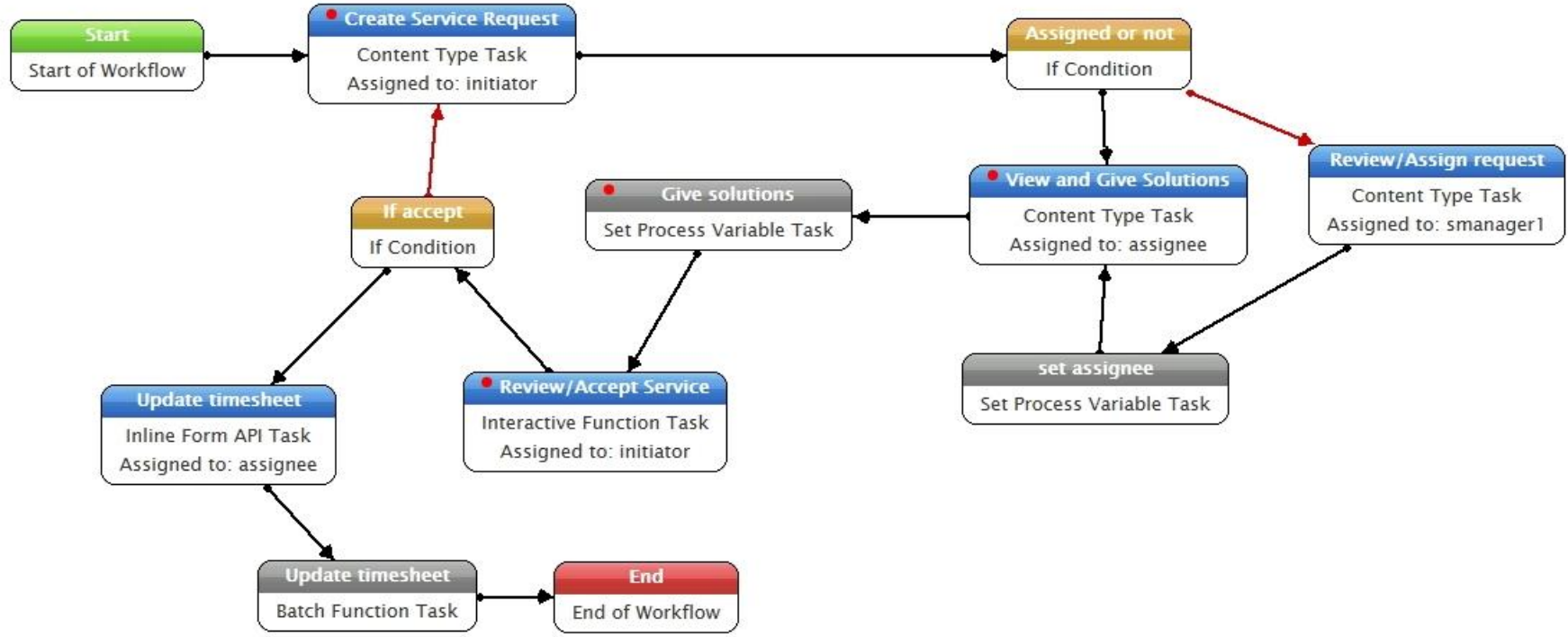

Fig. 4The workflow controlled by the backend Maestro module

\section{Corrective maintenance}

Please Press "Launch" to Start New Process: Select Workflow

- Launch

\begin{tabular}{llc}
\hline Flow Name & Task Name & Assigned \\
\hline Service request & Create Service Request & $10 / 03 / 16$ \\
\hline $\begin{array}{l}\text { Corrective maintenance } \\
\text { workflow }\end{array}$ & Create service request & $10 / 03 / 16$
\end{tabular}

\section{Corrective maintenance}

(a)

\section{Maestro menu}

My Task Console

My Workflows

All Maestro Workflows

All Tasks
Please Press "Launch" to Start New Process: Select Workflow

\begin{tabular}{llll}
\hline Flow Name & Task Name & Assigned \\
\hline$*$ Service request & Review/Assign request & $10 / 03 / 16$ \\
\hline Service request & Assign request & $10 / 24 / 15$
\end{tabular}

(b)

\section{Maestro menu}

My Task Console

My Workflows

Fig. 5(a) Maestro task console logged in as machine tool user;

(b) Maestro task console logged in as service manager in machine tool manufacturer 


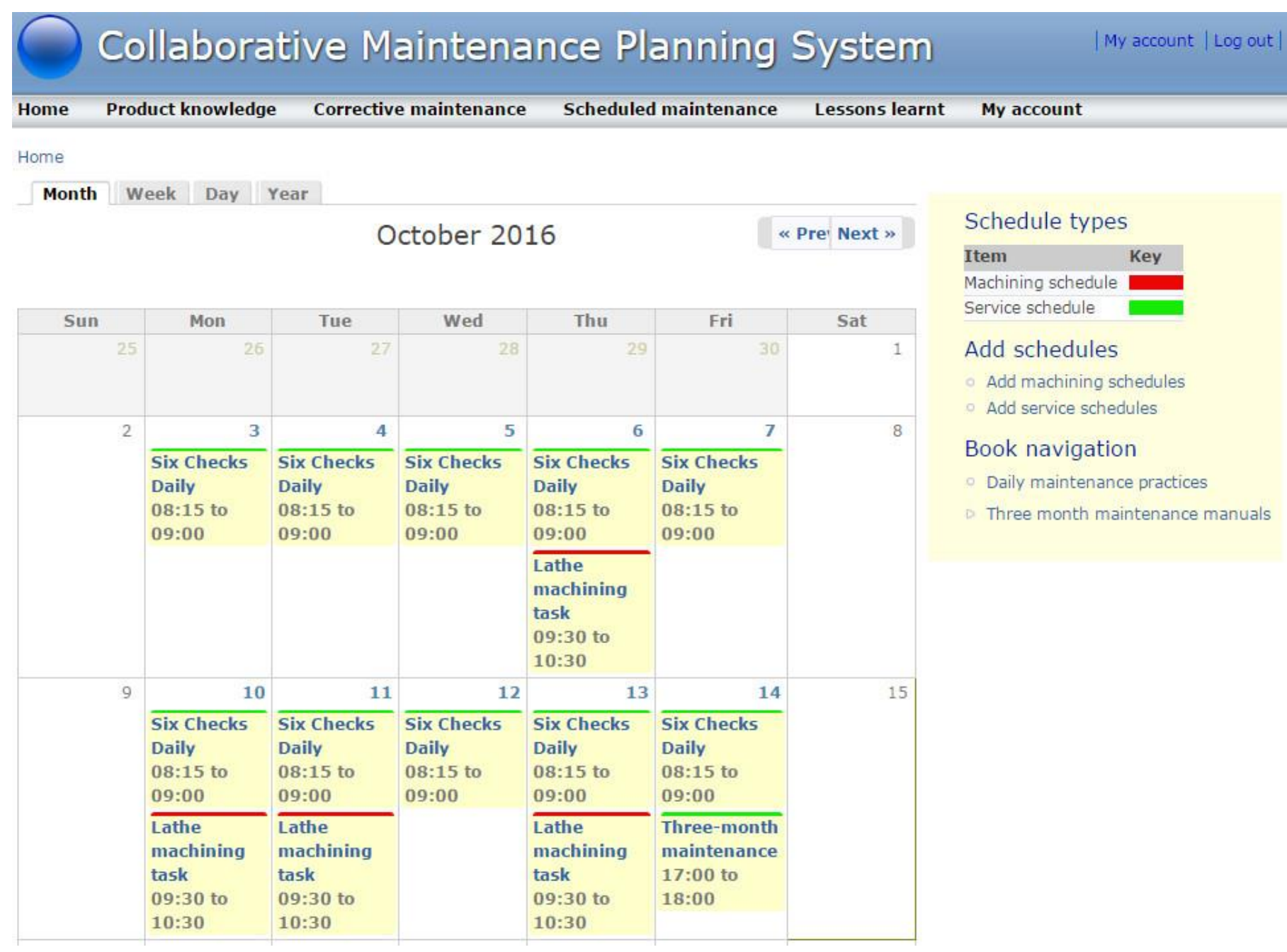

Fig. 6 Maintenance and machining schedules created by different stakeholders

\section{Ontology based knowledge representation}

Although CoMPS system can deal with maintenance and service planning management issues, it still needs some data and information from other systems in different organizations, such as the machine tools' production schedule is needed by the service provider to make service plans. Different systems have their own knowledge representation languages, thus the interoperability between these systems should be solved.

Ontology is widely used for semantic knowledge representation especially in computer science. The term "Ontology" represents domain entities and their relationships by means of classes and relations, because "knowledge does not only contain information, but also the relationships among information items" [26]. Thus ontology allows representing the semantics of maintenance knowledge in a formal way that the computer can interpret to avoid ambiguity in a context, which enables the implementation methods of advanced computer science to manage, search and enrich the knowledge [27]. In order to achieve interoperability by representing knowledge effectively and formally in this project, Ontology is used to represent machine tool maintenance and service related knowledge in CoMPS.

The machine tool maintenance and service knowledge can be classified into different types according to their functions in the maintenance process (as seen in Fig. 7). Product knowledge is the foundation of maintenance. There are different product models, and they have many components among which some key components have to be paid attention to. Each component of the machine tool (product) has a failure mode. It is this kind of knowledge that provides the input to maintenance. Based on the failure modes of the components of machine tools, service solutions including methods, process and workflow can be planned, so that service cases and lessons learnt are retrieved and modified. Services cannot be executed successfully without resource knowledge (including personnel, spare parts, consumables, tools and technology), and other supportive knowledge such as 
stakeholders' knowledge and constraint knowledge.

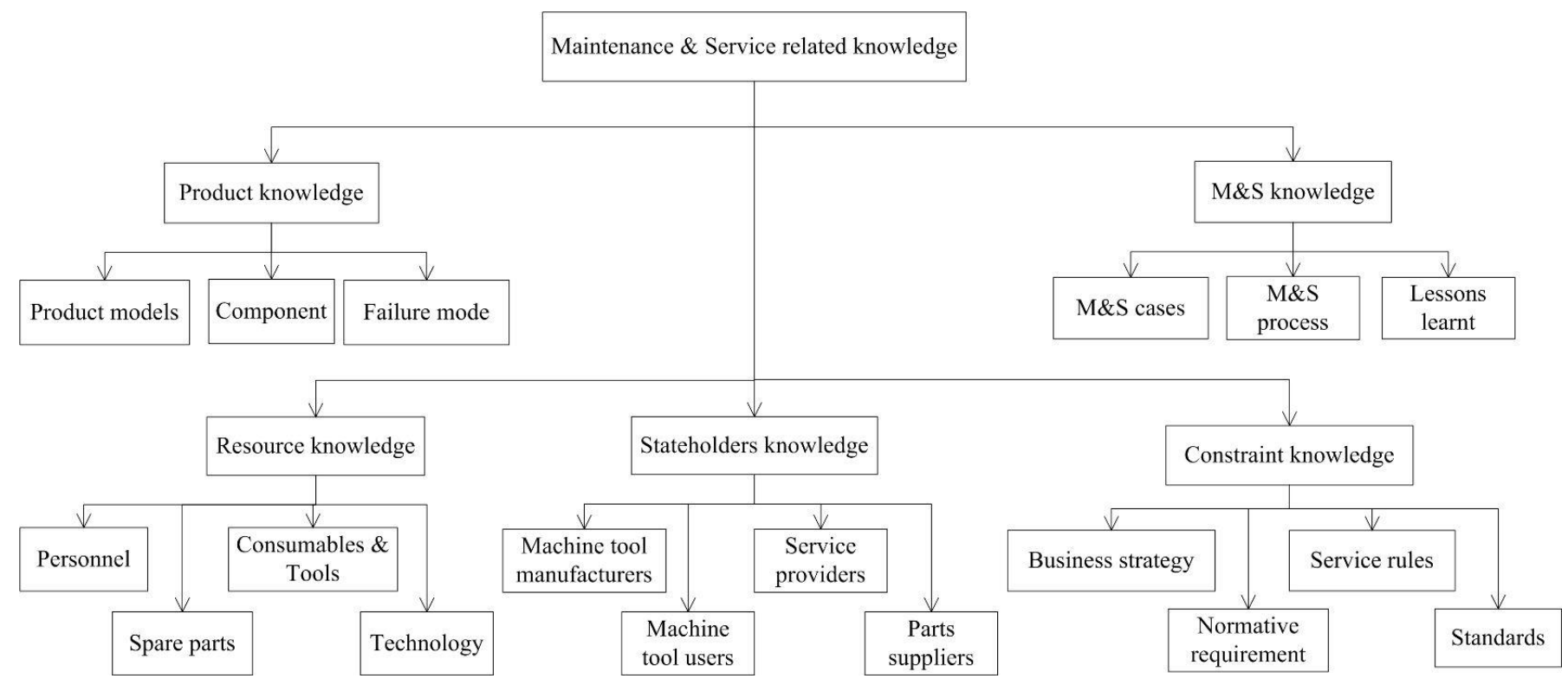

Fig. 7 Machine tool maintenance and service related knowledge

Based on the knowledge management requirement above, the Ontology is established using Protégé, an Open Source ontology development tool in the academic community developed by Stanford University, to formalise the knowledge for machine tool maintenance and service [28]. Another reason for using Protégé is that it supports almost all kinds of ontology representation language such as $\mathrm{XML}, \mathrm{RDF}(\mathrm{S})$, OIL, DAML+OIL and OWL. It is more generic in the aspects of runtime environment, extensibility and inheritability, diversity of storage than many other ontology editing tools. Protégé has open port and supports a lot of plugins, such as Jena, Racer and myCBR for different purposes. Fig. 8 shows the ontology of a typical machine tool (with sub-systems) constructed by Protégé, which consists of maintenance and service (M\&S) knowledge ontology, product knowledge ontology, stakeholders' knowledge ontology, resource and constraint knowledge ontology.

In order to apply the ontology model, Fig. 9 shows how ontology helps the interoperability between enterprise information system and the proposed CoMPS: Ontology defines the consistent concepts and their relationships in the field. Jena is used to transfer ontology between Protégé and the database: MySQL. Other enterprise information systems such as ERP, MES could communicate with the related database, and then data and information from these systems can be shared with CoMPS system. 


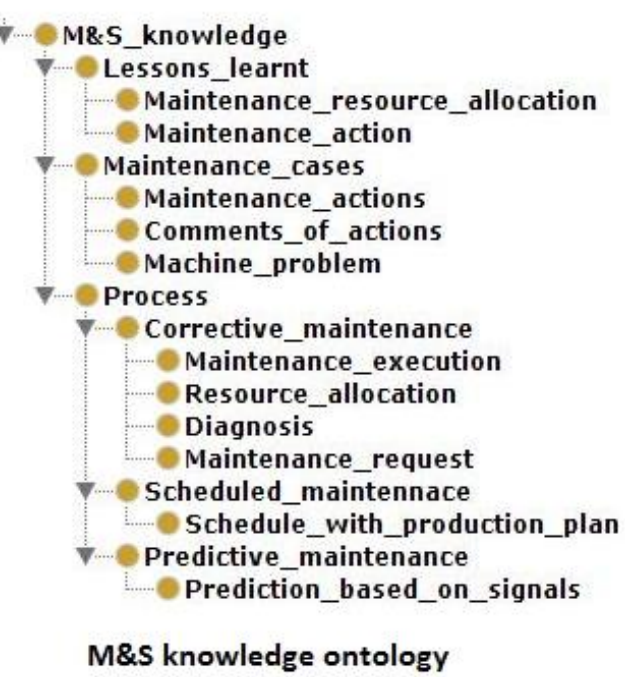

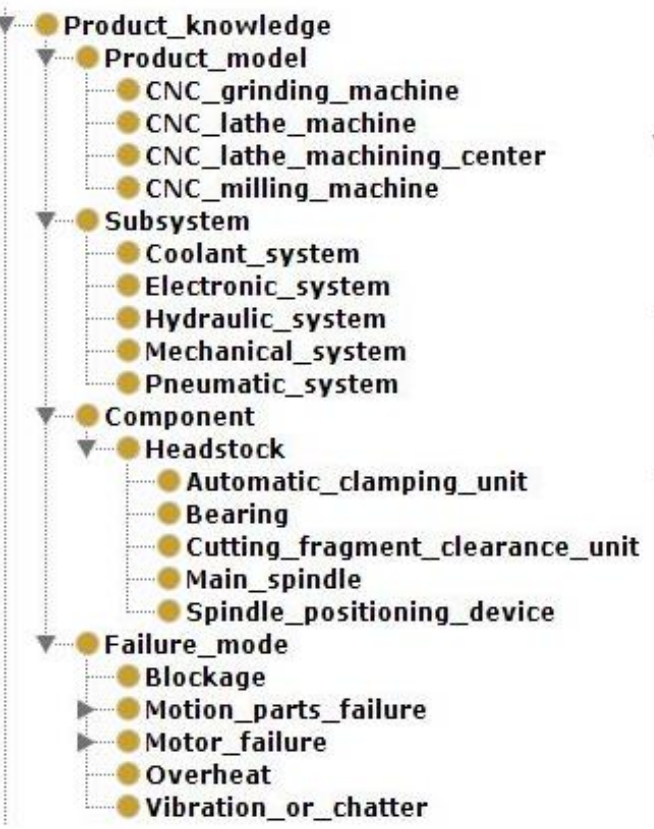

Product knowledge ontology

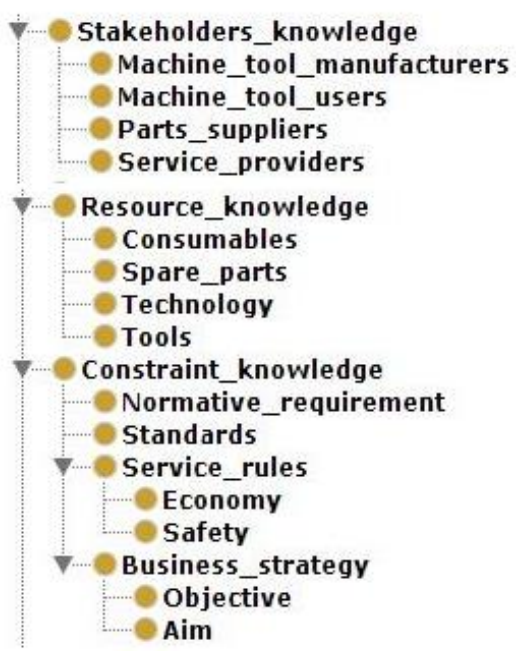

Stakeholders, Resource, Constraint knowledge ontology

Fig. 8 Ontology of maintenance and service related knowledge of a typical machine tool

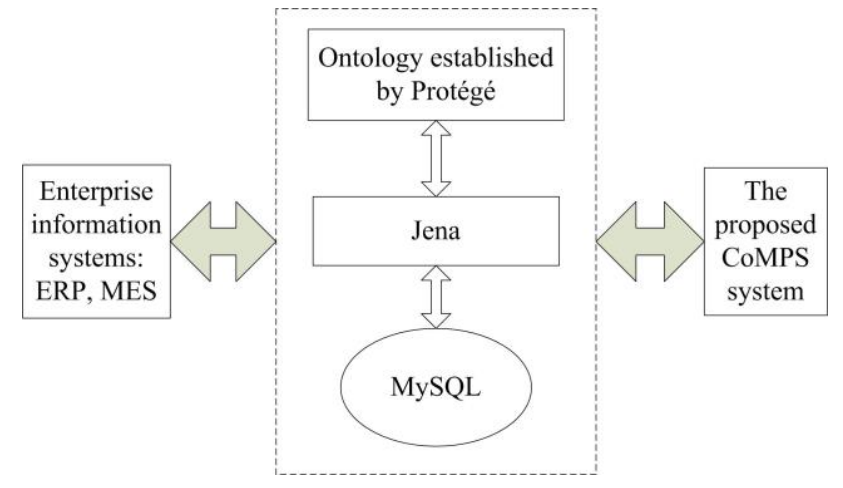

Fig. 9 The interoperability between enterprise information systems and the CoMPS system by Ontology

\section{Example used to evaluate CoMPS}

During system implementation, an example machine tool (CH7520C) was used to test and evaluate the developed CoMPS. The machine tool is manufactured by a Chinese machine tool manufacturer. It is a typical high value Computer Numerical Control (CNC) machining centre with integrated drilling, milling and tapping functions. The machine is designed with high strength and dynamic-static stiffness, and with advanced design of the mechanical structure, protection, coolant and safety system. Some key parameters of the machine tool are: maximum turning diameter: $\varnothing 280 \mathrm{~mm}$, main spindle speed: $40-4000 \mathrm{r} / \mathrm{min}$, feed rate in $\mathrm{X}$ and $\mathrm{Z}$ axis are 12 and $16 \mathrm{~m} / \mathrm{min}$ respectively, the number of tools in the magazine: 12, minimum angle of the $\mathrm{C}$ axis for milling: 0.001 degrees, lathe bed angle: 45 degrees. This type of CNC machine tool is of high machining speed, high precision and long life.

The machine tool user in this case is a company in Nanjing (a city in China) that machines aviation parts. Due to the high quality requirements for the high performance parts by its aviation customer, the maintenance and service for this machine tool is important to achieve the required high machining performance. The maintenance and 
service is executed by two kinds of service providers: the user company itself and the service branch from the machine tool manufacturer. The service providers vary according to the frequency of maintenance and service. For example, the scheduled maintenance for $\mathrm{CH} 7520 \mathrm{C}$ includes Daily Care, Weekly Care, Maintenance Every Three Months, Maintenance Every Six Months and Maintenance Each Year. The daily, weekly and three-month maintenance will be executed by the user company themselves, since these types of services are relatively easy and more frequent, while the half-yearly and yearly maintenance and service will be executed by highly qualified engineers in the service branch of the machine tool manufacturer, including a complete inspection of the machine tool.

When selling the machine tool, the machine tool manufacturer will add maintenance recommendations through the CoMPS system for users to make general plan. Since the user company has machining tasks every day, the machine tool's machining scheduling will be added on the CoMPS system by the user. Then the system has enough information for service providers to make service schedules based on practical arrangements. Actually Fig. 6 shows the real maintenance and service schedules and machining schedules for a CNC machine tool type: CH7520C. Inside of each schedules, there are detailed schedule arrangements, for example, one the day of $14^{\text {th }}$ October, there is a three-month maintenance schedule, the details of this schedule such as the service type, scheduled time, scheduled tasks (in Body field) and the related machine can be found in Fig. 10, the related machine indicates the objects of this schedule, it is linked to the relevant machine so that all the schedules and other arrangements of this machine can be found in that page.

\title{
Three-month maintenance
}

\author{
View Edit \\ admin - Tue, 05/17/2016 - 17:05 \\ Service type: \\ Preventive maintenance s Time-based maintenance ? Three-month maintenance
}

\section{Schedules: \\ 4 months 5 days ago \\ 2 months 2 days ago \\ 4 weeks 18 hours hence}

Body:

\begin{tabular}{|l|l|l|}
\hline Actions & Component & Executor \\
\hline Check and grease the chain on the chip conveyor. & Chip conveyor & Machine tool user \\
\hline Check and clean the filters on the coolant tank. & Coolant system & Machine tool user \\
\hline
\end{tabular}

Related machine:

CH7520C-2006-01

Fig. 10 An example of services schedules for a CNC machine tool type CH7520C

\section{Summary and conclusions}

CNC machine tools are special products, because its quality not only affects the profits of the machine tool manufacturers, but also affects the quality of manufactured parts in manufacturing systems. Furthermore, the maintenance and service activities require different stakeholders to collaborate with each other to achieve effective, 
efficient and satisfactory maintenance operations. Current and previous research in product service systems and computerised maintenance systems mainly focused on complex products rather than the machine tools that manufacture products. Therefore, one main novelty of this research is that the special requirements and problems in maintaining high value machine tools in a production system and in the real life business context have been investigated, and a Collaborative maintenance planning system has been developed. The machine tools are 'products' from maintenance point of view, and they also make other products from the manufacturing systems and production planning point of view.

The proposed system could connect different stakeholders during machine tools' life cycle for them to collaborate with each other efficiently. In addition, this system is able to manage dynamic knowledge including maintenance plans and lessons learnt compared with traditional enterprise information systems which only manage static information; The Web-based platform makes it easier for knowledge sharing and reuse despite geographical distance among stakeholders.

Since the proposed CoMPS system is developed using Open Source content management system - Drupal, which has fundamental advantages over other engineering information systems. Thus another main novelty of this research is the exploration of the potential application of advanced Content Management Systems in the engineering domain which has been so far dominated by traditional engineering information systems such as CAE, ERP and PLM systems. Content Management Systems are powerful information management systems widely used in business, financial and government organisations. This research proves that an Open Source Content Management System - Drupal can also be used in the engineering applications for managing engineering knowledge. The result for the example machine tool (CH7520C) proves that the developed system CoMPS has several advantages over traditional engineering information management systems in that:

- It is easier and quickerto generate a customized information system, since it supports users to 'configure' the system settings rather than undertake a lot of 'programming';

- It allows to download contributed modules and extend the modules' functionality thus saves a lot of time from creating modules from scratch;

- The RESTful service in Drupal provides APIs for other software to use knowledge of this system, and this can be achieved by a RESTful service module rather than coding it, which is another advantage compared with traditional engineering systems; and

- It is more flexible and user friendly because of the social media style which makes it easy for stakeholders to collaborate.

Early feedback and comments from engineers and manufacturing managers on the maintenance planning results for the example machine tool are very positive. They indicated that companies using future commercial systems like the prototype system CoMPS would be able to significantly improve efficiency and accuracy of planning maintenance operations and schedules, and be able to maintain the system by themselves with minimum or no support from software vendors. Furthermore, companies could significantly enhance communication: engineers can create their own blogs or discussion forums which allow peers to comment on and discuss project related problems with each other. Apart from that, with certain modules such as Feed Module, companies could keep up to date with information from other software or websites, for example, the machine tools' production task plan could be imported in the maintenance management system made by Drupal, and users can stay in one system rather than visit different software back and forth to check that information, thus much unnecessary time waste is avoided. More importantly, Drupal supports multilingual sites development which is good for international companies to keep their website consistent. This system has not yet included the predictive maintenance module. In the subsequent development, this module will be added to the system. Besides, the achievement of the predictive maintenance module requires online data input of machine tool performance, the integration between data acquisition system and the CoMPS system is 
another problem to be solved.

\section{Acknowledgements}

This research was funded by China Scholar Council grant (Ref: 201206840032) to sponsor a joint PhD project between Nanjing University of Science and Technology (China) and UK Universities. The PhD researcher (first author of this paper) spent two years in the UK and jointly supervised by senior UK academics (co-authors of this paper) throughout her $\mathrm{PhD}$ study. The authors would like to thank the engineers and managers of the collaborating companies in both UK and China who have provided valuable advice and acted as interviewees during the study.

\section{References:}

[1] KPMG, Industrial Manufacturing Megatrends $\begin{array}{llll}\text { Research, } & 1 & \text { June } & 2016 .\end{array}$ www.kpmg.com/uk/manufacturing.

[2] Masood T, Roy R, Harrison A, Xu Y, Reeve S, Integrating through-life engineering service knowledge with product design and manufacture, Int. J. Comput. Integ. M. 28(1) (2015) 59-74, http://dx.doi.org/10.1080/0951192X.2014.900858.

[3] Tran T, Park JY, Development of a novel set of criteria to select methodology for designing product service systems, Journal of Computational Design and Engineering 3(2) (2016) 112-120, http://dx.doi.org/10.1016/j.jcde.2015.10.001.

[4] Metso L, Marttonen S, Thenent NE, Newnes LB, Adapting the SHEL model in investigating industrial maintenance, Journal of Quality in Maintenance Engineering 22(1) (2016) 62-80, http://dx.doi.org/10.1108/JQME-12-2014-0059.

[5] Borsato M, Bridging the gap between product lifecycle management and sustainability in manufacturing through ontology building, Comput. Ind. 65(2) (2014) 258-269, http://dx.doi.org/10.1016/j.compind.2013.11.003.

[6] Sakao T, Ölundh Sandström G, Matzen D, Framing research for service orientation of manufacturers through PSS approaches, Journal of Manufacturing Technology Management 20(5) (2009)

754-778, http://dx.doi.org/10.1108/17410380910961082.

[7] Zhu H, Gao J, Li D, Tang D, A Web-based Product Service System for aerospace maintenance, repair and overhaul services, Comput. Ind. 63(4) (2012) 338-348, http://dx.doi.org/10.1016/j.compind.2012.02.016.

[8] Rastegari A, Mobin M, Maintenance Decision Making, Supported By Computerized Maintenance Management System, in: 2016 Annual Reliability and Maintainability Symposium (RAMS), 2016, pp. 1-8, http://dx.doi.org/10.1109/RAMS.2016.7448086.

[9] Clair KM, Metadata Best Practices in Web Content Management Systems, Journal of Library Metadata 4(12) (2012) 362-371, http://dx.doi.org/10.1080/19386389.2012.735562.

[10] Muller A, Crespo Marquez A, Iung B, On the concept of e-maintenance: Review and current research, Reliab. Eng. Syst. Safe. 93(8) (2008) 1165-1187, http://dx.doi.org/10.1016/j.ress.2007.08.006.

[11] Macchi M, Crespo Márquez A, Holgado M, Fumagalli L, Barberá Martínez L, Value-driven engineering of E-maintenance platforms, Journal of Manufacturing Technology Management 25(4) (2014)

$568-598$ http://dx.doi.org/10.1108/JMTM-04-2013-0039.

[12] Wandt K, Karim R, Galar D, Context adapted prognostics and diagnostics 1 (2012) 541-550

[13] Ramachandra CG, Srinivas TR, Shruthi TS, A Study on Development and Implementation of a Computerized Maintenance Management Information System for a Process Industry, International Journal of Engineering and Innovative Technology (IJEIT). 2, 2012, pp: 93-99, http://www.ijeit.com/vol\%202/Issue\%205/IJEIT1 412201211_18.pdf.

[14] Nourelfath M, Châtelet E, Integrating production, inventory and maintenance planning for a parallel system with dependent components, Reliab. Eng. Syst. Safe. $101 \quad$ (2012) 59-66, http://dx.doi.org/10.1016/j.ress.2012.02.001.

[15] Rivera-Gómez H, Gharbi A, Kenné JP, Joint production and major maintenance planning policy of a manufacturing system with deteriorating quality, International Journal of Production Economics 146(2) (2013) 575-587, http://dx.doi.org/10.1016/j.ijpe.2013.08.006. 
[16] Liu C, Li Y, Shen W, Dynamic feature modelling for closed-loop machining process control of complex parts, Int. J. Comput. Integ. M. 28(7) (2014) 753-765, http://dx.doi.org/10.1080/0951192X.2014.900870.

[17] Li Y, Wang W, Liu X, Ma Y, Definition and recognition of rib features in aircraft structural part, Int. J. Comput. Integ. M. 27(1) (2013) 1-19, http://dx.doi.org/10.1080/0951192X.2013.799784.

[18] Marquez AC, Gupta JND, Contemporary maintenance management: process, framework and supporting pillars, Omega 34(3) (2006) 313-326, http://dx.doi.org/10.1016/j.omega.2004.11.003.

[19] Tretten P, Karim R, Enhancing the usability of maintenance data management systems, Journal of Quality in Maintenance Engineering 20(3) (2014) 290-303, http://dx.doi.org/10.1108/JQME-05-2014-0032.

[20] Alalwan JA, A taxonomy for decision support capabilities of enterprise content management systems, The Journal of High Technology Management Research 24(1) (2013) 10-17, http://dx.doi.org/10.1016/j.hitech.2013.02.001.

[21] Patel SK, Rathod VR, Parikh S, Joomla, Drupal and WordPress - A Statistical Comparison of Open Source CMS. In: 3rd International Conference on Trends in Information Science \& Computing, IEEE, Chennai, India, 2011, http://dx.doi.org/10.1109/TISC.2011.6169111.

[22] Yen C, Yen C, Hsu J, A Web-based CMS/PDM Integration for Product Design and Manufacturing. In: IEEE International Conference on e-Business Engineering (ICEBE), IEEE, Xi'An, China, 2008,
http://dx.doi.org/10.1109/ICEBE.2008.104.

[23] Staccini P, Bordonado C, Alet J, Joubert M, Dufour JC, Fieschi M, A Customized Open Source Content Management System to Support Collaborative Distance Learning: The J@LON Platform. In: Twentieth IEEE International Symposium on Computer-Based Medical Systems (CBMS '07), IEEE, Maribor, Slovenia, 2007-01-01, 2007, http://dx.doi.org/10.1109/CBMS.2007.4.

[24] RealStoryGroup, Real Story Group - Make Better Technology Decisions, 2016-05-01. https://www.realstorygroup.com/Vendors-Evaluat ed/.

[25] Babbar P, Ghag A, Singh N, Hess M, The Drupal Overview | Drupal.org, 2016-04-28. https://www.drupal.org/.

[26] Paul M, Engelhart M, Rus I, Lindvall M, Knowledge management in software engineering, IEEE software 3(19) (2002) 26-38

[27] Brandt SC, Morbach J, Miatidis M, Theißen M, Jarke M, Marquardt W, An ontology-based approach to knowledge management in design processes, Comput. Chem. Eng. 32(1-2) (2008) 320-342,

http://dx.doi.org/10.1016/j.compchemeng.2007.04. 013.

[28] Fei G, Gao J, Owodunni D, Tang X, A Model-driven and Knowledge-based Methodology for Engineering Design Change Management, Computer-Aided Design and Applications 8(3) (2011) 373-382, http://dx.doi.org/10.3722/cadaps.2011.373-382. 